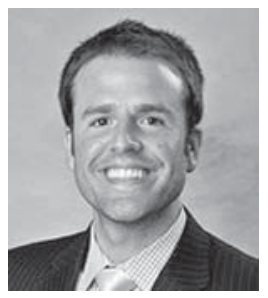

Benjamin Preyss, a 2011 Pisacano Scholar, is a 4 th-year medical student at the University of Illinois at Chicago College of Medicine (UIC), where he is pursuing a joint MD/MBA degree. He graduated with honors from The University of Chicago with a Bachelor of Arts in Human Development. He was a multiple Dean's List recipient and was awarded Distinct Honors in Human Development for the presentation of his senior thesis. Benjamin was also captain of the men's varsity soccer team. In addition, he worked as campus manager for Teach for America during the last 2 years of college and traveled to the indigenous villages of the Oaxaca Valley in Mexico as a student leader on multiple short-term medical mission trips.

Prior to medical school, Benjamin worked as a research consultant with one of the nation's leading research and consulting firms addressing the organization and financing of health care for vulnerable populations.

As a recipient of the Albert Schweitzer Fellowship, Benjamin has worked to create and implement a health and wellness curriculum for Urban Initiatives - an extracurricular program working with over 500 elementary students in some of Chicago's most underserved communities. He recently began serving as a principal mentor to formerly homeless adolescents and young adults as part of a mentoring pilot program with Schweitzer Fellows for Life.

Benjamin is a member of UIC's Urban Medicine program, a unique 4 -year medical school curriculum preparing physician-leaders to serve urban communities. He was recently inducted into UIC's chapter of the Gold Humanism Honor Society, a national organization recognizing outstanding humanistic character and performance by medical students.

While completing his MBA curriculum, Benjamin was awarded the Grand Prize at UIC's campus-wide business competition for leading a management team in the creation of a business plan to establish a new faithbased community health center in Chicago's Humboldt Park community.

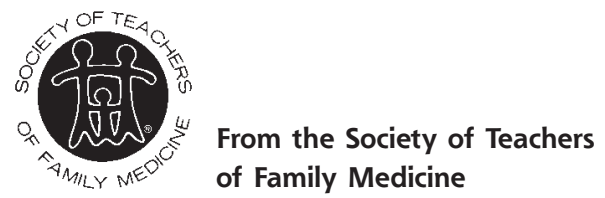

Ann Fam Med 2011;9:556-557. doi:10.1370/afm.1329.

\section{BUILDING A HIGH-PERFORMANCE ORGANIZATION FOR THE DISCIPLINE}

What does it take to build a high-performance organization? Robert Graham, MD, Robert Wood Johnson Foundation national program director of Aligning Forces for Quality and executive director of the STFM Foundation Bishop Fellowship Program, has done extensive work and thinking about how to define high-performance organizations. The fruits of his labors point to 6 things that high-performance organizations do well:

- Plan regularly

- Execute in a disciplined manner

- Change/evolve

- Maintain success over time

- Show resilience in the face of adversity

- Develop people

This report focuses most directly on the first 2 elements, highlighting the work the STFM Board and Strategic Planning Committee have recently done to move us in this direction.

\section{Plan Regularly}

- There is a strategic plan that guides decision making and resource allocation choices

- The plan is reviewed and revised regularly

\section{Execute in a Disciplined Manner}

- There are clear action steps for each plan element, and a specific person/group responsible

- Process in accomplishing tasks is tracked regularly and visibly with results fed back into the planning process

\section{Introducing STFM's 2012-2014 STFM Strategic Plan}

The STFM Board of Directors implemented a strategic planning process in 2011 to develop a 3-year plan and a process for utilization, measurement, updating, and for adding new and sunsetting old programs. This was developed with extensive discussions by the Strategic Planning Committee; interviews of the leaders, nonmembers, and general members; focus groups; and a member needs survey.

This research resulted in the identification of 5 interdependent key priority areas for STFM to address over the next 3 years. 
What does this mean to our stakeholders?

We are going to have a sharper focus on activities and initiatives that you have helped identify as high priority to you and the discipline. For example, based on feedback from you, we plan to create a national residency curriculum, likely in partnership with others.

This also means that the bar has been raised for our existing programs. Their continuation will depend on the extent to which they continue to have a significantly positive impact on our members and whether they contribute in a meaningful way to advancing family medicine. Without this critical examination, we run the risk of creating an even larger inventory of programs and not having the resources to give the highest impact programs their proper attention. By trying to do everything, we will do few of the important things well and will become a mediocre and irrelevant organization.

\section{STFM Strategic Priorities (Not Listed in Rank Order)}

Professional and Leadership Development. STFM will be the leader in training, leadership development, and creation of information that improves family medicine education and teaching.

Scholarship and Innovation. STFM will be the authority for innovation and research in family medicine education.

Workforce Development. STFM will promote family medicine workforce development through innovation, curriculum development, and practice redesign in teaching sites.

Professional Relationships. Relationships developed through STFM will enhance the professional well-being, vitality, and growth of members and the discipline.

Policy Advocacy. STFM will develop and utilize its members' expertise to positively influence legislation and regulations that have an impact on family medicine education and workforce development.

The strategies related to this plan can be found on the STFM Web site. The staff and Board are adding timelines and responsibilities and already acting on several of the strategies in the plan.

Creating a high-performance organization is much more than developing a strategic plan. There are other critical elements integral to our success that require specific attention, such as a focus on innovation and being relevant to members and an ability to adapt to and manage change. The main takeaway should be that STFM leadership is paying attention to all these factors. We're a work in progress but a Society that's headed in the right direction.

Stacy Brungardt, CAE, STFM Executive Director

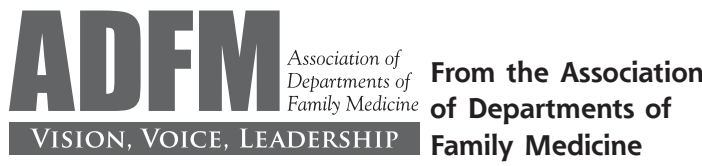

Ann Fam Med 2011;9:557-558. doi:10.1370/afm.1326.

\section{LEADERSHIP IN AN AGE OF UNCERTAINTY AND AUSTERITY}

Not in recent history have times for academic family medicine been so uncertain. As recently reported in the New England Journal of Medicine, ${ }^{1}$ we are witnessing health care policy during an age of acute uncertainty, but long-term austerity.

We are facing a myriad of challenges that are posing a test for everyone in the discipline-whether chairs, residency directors, faculty, or trainees. Indeed, it is very difficult to determine which direction the wind is blowing and how to prepare for the next few years, let alone the next few decades. Below are enumerated but a few of the more common and extreme scenarios we are anticipating:

- The fate of health care reform is unclear. The Accountable Care Act is under threat in the courts and in the political process. If it goes forward, there will be fundamental changes to Medicaid and Medicare that will influence patients, patients' choice, and the institutions where they seek care

- Clinical revenues may be severely curtailed. The rate of medical inflation is unsustainable and significant cuts may be on the near horizon, starting with Medicare's sustainable growth rate (SGR)

- How medical services are paid for is already undergoing profound alterations and more changes are virtually certain to be implemented. Some insurers, such as in Massachusetts, are considering paying less to high-spending hospitals, while bundled payments are being strongly considered

- Graduate medical education funding is threatened and may be on the Congressional chopping block in the near future

- NIH funding lines are extraordinarily low with no signs of improvement in the near future-or other sources to compensate for the drop

- All institutions that support family medicine are under threat and many are in economic straitswhether hospitals, medical centers, or medical schools

What is clear is that budgets for departments and residencies in family medicine are likely to come under growing pressure in the next few years-and many have already, as we face the potential "perfect storm" of 